\title{
'Digital Workplace: Auf das richtige Tool kommt es an?
}

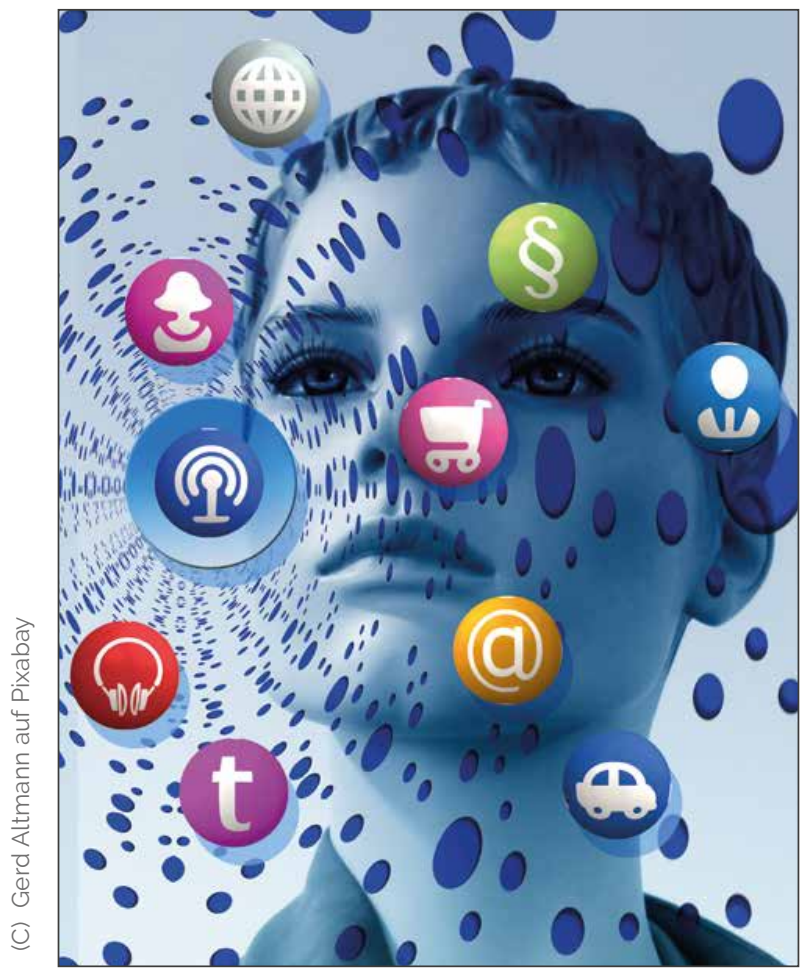

Der Modern Workplace ist das Ziel von Digitalisierungsbestrebungen. Das heißt: Die Mitarbeiter sollen zeit-, orts- und endgeräteunabhängig arbeiten können. Alle Unternehmensanwendungen - und dort gespeicherten Daten - müssen dafür optimal vernetzt sein. Kollaboration, Kommunikation in Echtzeit und gemeinsamer Informationszugriff werden in diesem Zuge zur Selbstverständlichkeit. Der Weg zum Arbeiten 4.0 führt dabei, nahezu zwangsläufig, über eine IT-Lösung. Unternehmen brauchen ein Tool, das für interne und externe Stakeholder zur zentralen Wissensdrehscheibe wird. Viele Organisationen setzen dabei auf Microsoft 365. Auch die GSuite von Google ist weit verbreitet. Worauf es bei diesen beiden Anwendungen ankommt, welche Features sie liefern und worin sie sich unterscheiden, lesen Sie in unserem aktuellen Titelthema "Tools \& Methoden: Digital Workplace mit M365, GSuite \& Co." ab Seite 22. Dabei fällt auf: Für den Digitalisierungserfolg spielt die Auswahl des "richtigen“ Tools eine entscheidende Rolle. Noch viel wichtiger ist es aber, dass alle Mitarbeiter von Anfang an in das Projektvorhaben eingebunden sind und mit ihren Sorgen, Ängsten und Wünschen rund um die Digitalisierung ernst genommen werden. Begleitendes Changemanagement gilt daher als zentraler Erfolgsfaktor und wiegt wesentlich mehr als die reine Toolauswahl.

Eng verbunden mit dem Digital Workplace sind auch die Themen IT-Sicherheit und Datenschutz. Stichwort: EU-DSGVO. Wie es drei Jahre nach Inkrafttreten um Umsetzung und Strafverfolgung bestellt ist, das analysiert Rechtsexperte Martin Krings in seinem Fachartikel ab Seite 46. Nicht nur, aber auch bei Marketingaktivitäten ist der Datenschutz immer wieder ein viel diskutiertes Thema. Ab Seite 48 erfahren Sie, welche Auswirkungen das Ende des EU-US-Privacy Shields noch immer auf das E-Mail-Marketing hat. Und ab Seite 34 lesen Sie, wie Sie hyperpersonalisierte Kommunikation im Marketing einsetzen - und dadurch die Customer Experience deutlich erhöhen.

Darüber hinaus lesen Sie in der aktuellen Ausgabe von "wissensmanagement - Das Magazin für Digitalisierung, Vernetzung \& Collaboration", wie namhafte Unternehmen inre Digitalisierungsprojekte umgesetzt haben, darunter sind Firmen wie IBM, Goldbeck und die Technologiegruppe Harting.

Ich wünsche Ihnen eine wissensintensive Lektüre!

Ihr

Oliver Lehnert



